\title{
Business Outcomes of Product Repairability: A Survey-Based Study of Consumer Repair Experiences
}

\author{
Mostafa Sabbaghi ${ }^{\text {a }}$, Behzad Esmaeilian ${ }^{\text {c }}$, Willie Cade ${ }^{\text {d }}$, Kyle Wiens ${ }^{\text {e }}$, Sara Behdad ${ }^{\text {a b* }}$, \\ ${ }^{a}$ Industrial and Systems Engineering Department, University at Buffalo, SUNY, Buffalo, New York, USA \\ ${ }^{\mathrm{b}}$ Mechanical and Aerospace Engineering Department, University at Buffalo, SUNY, Buffalo, New York, USA \\ ${ }^{\mathrm{c}}$ Industrial and Systems Engineering, Northern Illinois University, DeKalb, Illinois, USA \\ ${ }^{\mathrm{d}}$ PC Rebuilders \& Recyclers Inc., Chicago, Illinois, USA \\ e iFixit Inc., San Luis Obispo, California, USA
}

\begin{abstract}
Product repair is a suggested post-purchase activity toward extending the useful lifespan of a product. However, repairability has not received sufficient attention by manufacturers. Even if the product repairability is not explicitly claimed by manufacturers, it is expected by consumers, thereby impacting their loyalty and future purchase recommendations. In this paper, the impact of consumers' product repair experiences on their future purchase and recommendation decisions is investigated. The study is based on a survey consisting of 8403 consumers who have had personal repair experiences in year 2013. A bivariate ordered probit model is used to estimate two correlated variables that jointly represent the future product sale, namely 'consumer future purchase decision' and 'purchase recommendations to friends and family'. It was found out that predictor factors such as usefulness of repair information, complexity of repair and consumers' willingness to repair a broken product have significant effect on the future purchase decisions and recommendations.
\end{abstract}

Keywords: Design for Repair, Product Repairability, Consumer Behavior, Product End-of-Use Recovery

\section{The Importance of Product Repairability}

The fast-growing stream of obsolete, but still functional products is becoming an economic and environmental crisis worldwide these days [1]. Whether it is planned by manufacturers [2] or not, a large proportion of unwanted used products are still functional either with or without minor defects. However do consumers tend to repair broken products and reuse them? What difficulties do consumers encounter when fixing their broken products? Do the difficulties during the repair process affect consumers' future repurchasing decision and the recommendations they provide to others?

Product repairability is a design feature that has been getting attention from communities, especially the remanufacturing industry. While designers may partially consider it at the early stages of design, it is not usually something claimed by manufacturers as a trump card, and therefore, it is not regarded as a policy toward increasing product credibility.

Most people express their annoyance with the high repair charges and count it as the main reason to avoid repairing a failed product [3]. If the repair mechanism is simplified in a way that it can be done even by individual consumers, then it will merely postpone the product replacement [4]. Proper product design seems a promising approach toward empowering consumers to repair. Although design for ease of repair is recommended, it is not always practical due to technology limitations and safety concerns [5]. It seems that the current product designs require significant revisions in terms of repairability. A concern then arises as to whether increasing products' repairability will benefit manufacturers or just pose extra costs to them? To answer this question, it is necessary to get the market and consumers feedbacks on the need for repairable products. 
The current paper aims to reveal the impact of repairability on the credibility of products in terms of a consumer's future purchases and recommendation decisions. The study has surveyed consumers on their prior repair experiences and established a relationship between their future purchase and recommendation decisions and a set of factors representing their previous repair experiences and attitude. The results of this paper will help companies determine whether they should consider 'design for empowering individual consumers to repair' as a strategy toward improving the likelihood of future purchases and recommendation decisions.

The rest of this paper is organized as follows: Section 2 provides a review of the related literature on product repairability. In Section 3, the questionnaire and the resulting dataset from the survey are described via descriptive statistical analysis. Then, a prediction model is explained in detail in Section 4. The results of the model and interpretation are discussed in Section 5. Finally, Section 6 concludes the findings.

\section{Literature Review}

How does a specific product become favored in the market? What are the product-related factors that bring more market share? The existing research has sought to decode the consumers' mind and their purchase behavior through characterizing the purchase decision-making process [6], [7]. Among all contributing factors, product design plays a vital role in the consumers' intricate decision-making. Prior to consumers' perception of product quality, appearance draws their attention to the product [8]. Consumers are thereupon deep in thought as to whether the product design meets their needs [9]. Henceforth, consumers will contemplate their assessment of the claims promised by manufacturers in the future purchase decisions [10]. The factors that consumers consider while making a purchase decision somehow reflect their actual post-purchase behavior. To cite evidence in support of this notion, Nieuwenhuis [11] reported that consumers who buy more durable products have a higher propensity to repair products over their lifespans. How much more likely they are to repair broken products and what repair experiences they have are two distinct factors that influence consumers' repurchases from a particular brand and purchase recommendation in the future.

Consumers do not believe in a product unless it delivers on the promises that have been already claimed, then product is called credible or believable [12]. Usually, products gain the confidence of consumers after they perceive the quality through the usage time. To address the product acceptance by consumers', a study done by Verbeke et al. [13] evaluated the Belgiumian consumers' perception of the claims offered on the nutrition and health advantages of different enriched products. In some cases, the product credibility starts earlier. Yang et al. [14] reported that people put higher credibility to products with higher sales volume, especially when they do not have any experience about the product quality. In their study, they showed that people select the mainstream movies to watch based on the box office revenue. In another study [15], Fotopoulos and Krystallis showed the positive impact of officially trusted quality label on the consumers purchase decision such that they even have willingness to pay more. Surprisingly, product appearance has an influence on green product acceptability [16].

Consumers' attitude toward product repair depends on many factors such as the repair procedure itself, consumers' traits, and requirements, and also the related market. Although public willingness to repair is soaring [17], there are still barriers that discourage consumers from fixing the broken products. Cooper [18] highlighted the repair cost as a key deterrent, which motivates consumers to choose a replacement option instead of repair. Howbeit, the initial price paid for the broken product may cast doubt on consumers' replacement decision [19]. However, the easy access to new products deters consumers from getting themselves into trouble with the repair [20] in which consumers are not fully certain of the repair outcomes. Consumers' attitudes and behavior toward repair/replacement problem are not likely concordant with each other. Consumer's emotional attachment to the current owned product affects their propensity to repair it [21]. This inclination is correlated with Eco-conscientious [21], personal 
lifestyle traits (e.g. frugality [22], product-retention tendency [23], product-care attentivity [24], and repairable products shopping tendency [16]), and finally socio-demographics factors such as age [25], income [22], education [22], and gender [26].

Given these points, is 'designing a repairable product' an economic motive for the manufactures to gain more profit via increasing sales and profit of repair services? While manufacturers and businesses can benefit from new design strategies, which result in repairable, durable, and longerlasting products, they rarely adopt these types of design policies. Instead, design for limited repairs and short-lived products are often adopted by businesses with the aim of increasing future demands and renew purchases [27], [28].

To alleviate the above-mentioned challenge on planned obsolescence by manufacturers, one of the most pressing areas of research in need of exploration is the connection between business models and design-for-lengthening-productlifespans strategies. Particularly, the possibility of adopting design-for-repair strategies in a business context and the associated consequences on business profitability has remained largely unexplored [29]. While a significant number of marketing studies have focused on how and why consumers choose to buy new devices, relatively little research has focused on consumers' usage and disposal behavior generally and repair specifically. Very little research has examined the repair behavior, its predictors, and its outcomes. The focus of prior research is mainly on discussing the sustainability consequence of repair [30], warranty time, after-sale service [31], and decision to repair versus replace [25], [30], [32] rather than discussing business outcomes of self-repair. Inconvenience of repair [33], personal traits [22], product retention tendency [23], and cost of repair [34], have been identified to be particularly important in predicting repair behavior.

Furthermore, besides the potential economic gains for manufacturers, the extension of a product lifespan by increasing the repairability can conserve the material and, consequently, reduce the environmental impacts. However, is it just a hypothesis that someday it may be noticed? The
Jevons' Paradox that is also called rebound effect [35] argues that the technological progress mitigates the environmental impact via improving the resource consumption efficiency; however, the environmental gains might be negated by an increase in demand for the promoted technology. Jevons Paradox has been extensively studied in the literature [36], [37]. The rebound effects are not only quantifiable in micro level, but also can be captured in macro scale, e.g., energy consumption in a country [38]. According to Jevons' Paradox [39], efficiently repairable and upgradable products may result in more spare parts consumption, while the product is no longer energy-efficient as it ages. Instead, it seems that a product design must be sufficiently repairable [40].

To the best of our knowledge, the economic consequence of repairability has not been studied in prior research. Therefore, the objective of this study is to determine whether manufacturers should adopt 'design for ease-of-repair' as a policy toward improving the chance of future purchases and recommendation decisions. The issue of repair can be translated to consumer's loyalty. A value analysis can be done based on available industry data to answer the following research questions: What would encourage repair behavior among consumers? What are the outcomes of repair behavior and how does product ease-of-repair influence repeated purchases and future demand?

\section{Description of Dataset}

A comprehensive survey was conducted by iFixit.com, a wiki-based website for repair manuals, to capture the consumers' attitude toward product repairability and other related issues. 8403 individuals responded to 27 questions. This survey consists of information about personal repair experiences, consumers' attitude toward product repair, common barriers to repair, and purchase decision behavior. All respondents have had some sort of personal repair experiences but not necessarily an equal level of experience in repair activities. Table 1 summarizes all the questions used in this study and the possible answers. They will be thoroughly discussed in the following subsections. 


\subsection{Dependent Variables: Consumer Loyalty to a Brand and Purchase Recommendation}

Product higher reliability or durability is considered an awkward marketing advertisement, therefore it is rarely seen that a firm advertises for more repairability. However, people expect to repair the broken products within a reasonable time and cost due to the fact that warranties are often offered for a limited time horizon. With respect to this hidden expectation, this paper attempts to discover how important product reparability is to consumers and whether it will impact consumers' future purchase decisions and recommendations or not. Measured in an ordinal scale, two questions have been asked from respondents about their repurchase decision and recommendations given to others based on their prior repair experiences:

- "If you successfully repaired a product, are you more likely to buy new products from the same company in the future?"

- "Have your experiences fixing your own products impacted the purchasing recommendations you give to your friends?"

Hereinafter, Consumer Loyalty Level (CLL) and Purchase Recommendation Level (PRL) are defined to characterize the above-mentioned questions. The possible answers to these questions have been listed in Table 1. Fig. 1 summarizes the respondents' answers to both questions. Since the possible answers are lexically different but indicate the same meaning, we replace them by new labels: Low, Medium, and High. Interestingly, consumers recommend a product in a conservative manner based on their repair experiences. 5\% of all respondents do not have much desire to purchase a product from the same brand after a successful repair, whereas $13 \%$ of all respondents less probable to recommend the device to others based on their repair experiences which is 1.6 times more. On the other hand, $47 \%$ of all respondents have strong inclination to repurchase from the same brand after a successful repair, but only $29 \%$ highly recommend the product to their friends, which is almost 38\% less. This difference is much less when the respondents have moderate opinion. Table 2 shows the relation between CLL and PRL. The value before parentheses represents the total number of respondents that choose a particular answer. For instance, 163 respondents (2\% of all respondents) choose (Low, Low) combination. An evidence exists for association between CLL and PRL $\left(\chi^{2}=896.15, p\right.$-value $\left.=0.000\right)$. Therefore, these two variables can be predicted by using a bivariate regression model. 
Table 1 List of questions in the survey with possible answers

\begin{tabular}{l|l}
\hline Question & \\
\hline $\mathrm{D}_{1}{ }^{*}:$ If you successfully repaired a product, are you more \\
likely to buy new products from the same company in the \\
future?
\end{tabular}

Fig. 1. Histogram of the dependent variables, CLL and PRL both given the prior repair experiences

Table 2 The relation between CLL and PRL both given the prior repair experiences

\begin{tabular}{|c|c|c|}
\hline \multirow{2}{*}{ Low } & \multicolumn{3}{|c|}{ Consumer loyalty level } \\
\cline { 2 - 3 } & Medium & High \\
\hline
\end{tabular}

\begin{tabular}{|c|c|c|c|c|}
\hline & & $379(5 \%)$ & $4039(48)$ & $3985(47 \%)$ \\
\hline $\begin{array}{l}\vec{\Xi} \\
\stackrel{\Xi}{\approx}\end{array}$ & 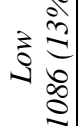 & $163(2 \%)$ & $613(7.3 \%)$ & $310(3.7 \%)$ \\
\hline 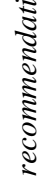 & 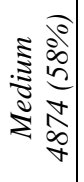 & $179(2.1 \%)$ & $2688(32 \%)$ & 2007 (23.9\%) \\
\hline 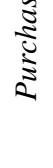 & 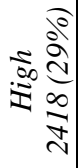 & $37(0.4 \%)$ & $738(8.8 \%)$ & $1668(19.8 \%)$ \\
\hline
\end{tabular}

\subsection{Explanatory Factors}

To predict the brand loyalty and recommendation levels discussed in Subsection 3.1, 32 factors are derived from 9 survey questions as predictor variables (Table 3). Most of them are defined as a dummy variable for better interpretation of results. These factors are categorized in four different classes based on the authors' point of view:

- Repair information propagation

- Convenience of repair

- Repair cost 
- Attitude toward repair

In the following subsections, these classes of factors are explained in details.

\subsubsection{Repair Information Propagation}

The lack of useful repair information and consumers' repair capabilities are among the factors that discourage consumers to repair their broken products [41]. Legislators, and initiatives, e.g. the European parliament and the Digital Right to Repair Coalition, urge manufacturers to share the repair information with their consumers and increase the general public awareness of product repair as one of the certain consumers' rights.

To show the impact of repair information on future consumers' purchase decisions and recommendations, two predictor factors including repair information use and repair information usefulness are derived from questions $F_{1}$ and $F_{2}$ in Table 1 . The first variable indicates the number of times a consumer uses the online-shared repair manuals. The second one asks respondents about how useful the repair information was to them.

\subsubsection{Convenience of Repair}

How easy is to repair a product? If a product is designed in such a way that faults are traceable, the failed component is reachable via simple disassembly process, repair process itself is straightforward, reassembly is doable, and the spare parts are accessible, then we can say that the product is repairable enough.

Two questions have been used to extract the convenience of repair: 1) The type of products that respondents feel comfortable fixing, and 2) the reasons they did not succeed in fixing a product. Respondents could select the category (ies) of products that are convenient for them to repair. Available product choices are categorized into six classes: electronics, small home appliances, large home appliances, vehicle, clothing, and furniture. In addition, if the respondents have unsuccessful repair experiences, they have been asked about the reasons why those happened. The set of reasons covers unavailability of spare parts, expensive spare parts, unavailability of required repair tool, timeconsuming repair, complexity of repair process, and unavailability of repair manual. Fig. 2 illustrates the
Pareto diagram of different reasons. The plot implies the point that complexity of repair seems more challenging for consumers compared to the accessibility to the repair information, required repair tools, and availability of spare parts.

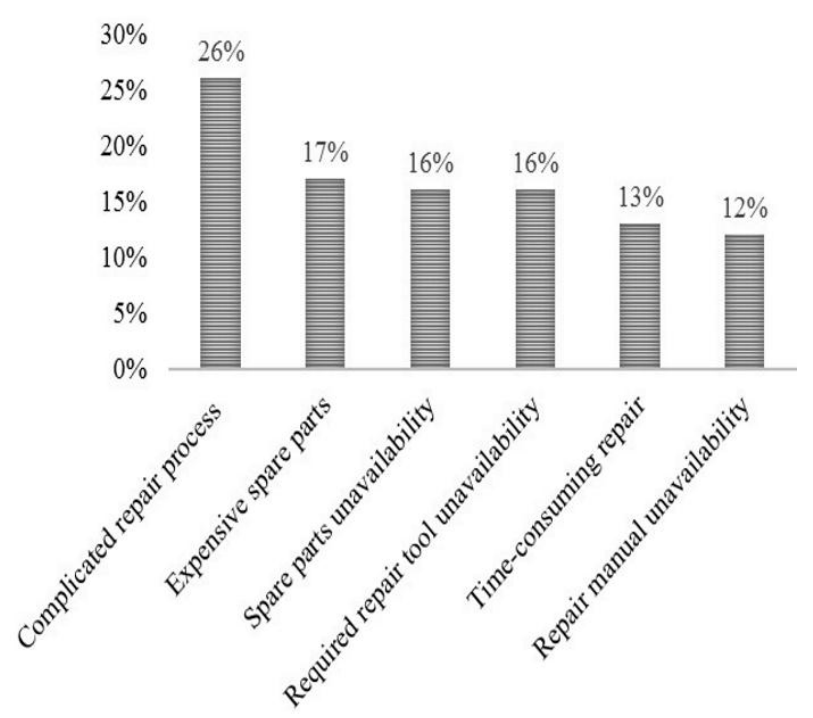

Fig. 2. The main reasons for an unsuccessful product repair with their occurrence percentage according to the consumers' former repair experiences.

\subsubsection{Repair Cost}

Consumers may have particular repair experiences that affect their future decisions. The total amount of repair cost that they spent over the last year is one of those experiences. They are asked to roughly estimate that value. We use numerous exchange rates to move all monetary values to a single currency. Fig. 3 shows the distribution of the amount of money that consumers spent on repair over year 2013. The analyses show that almost $80 \%$ of consumers spent less than $\$ 1,000$, while $19 \%$ of them spend between $\$ 1,000$ and $\$ 10,000$ and rarely spent more than $\$ 10,000$. Inside each ranges of cost, the amount of cost exponentially decreases. 


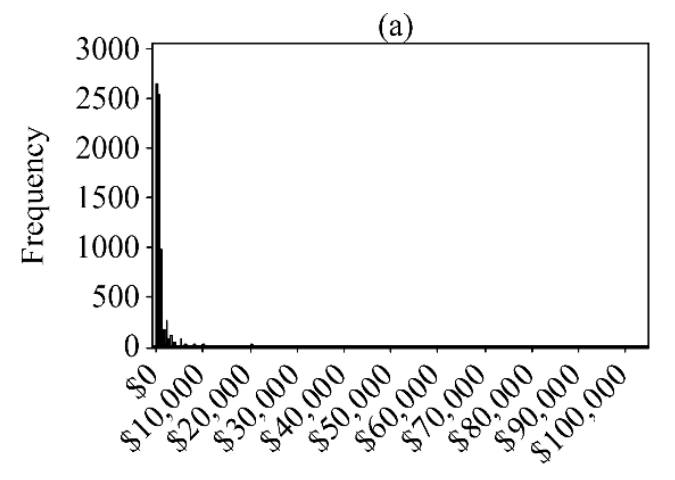

Total Repair Cost

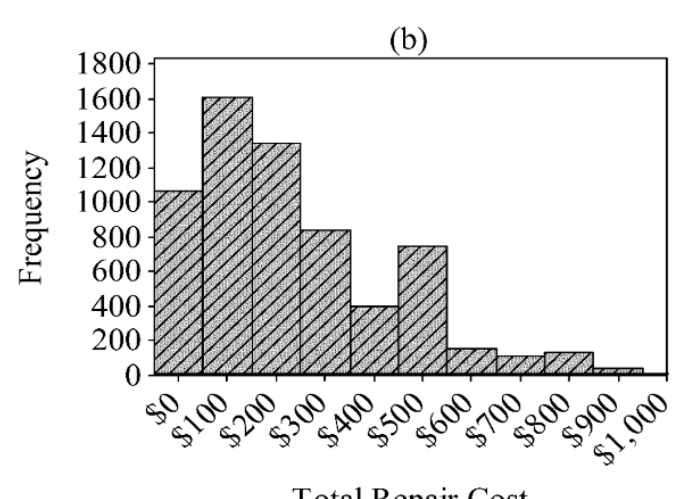

Total Repair Cost

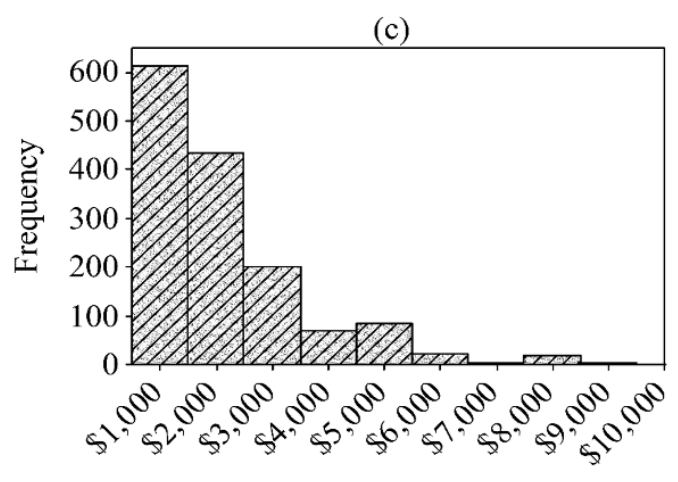

Total Repair Cost

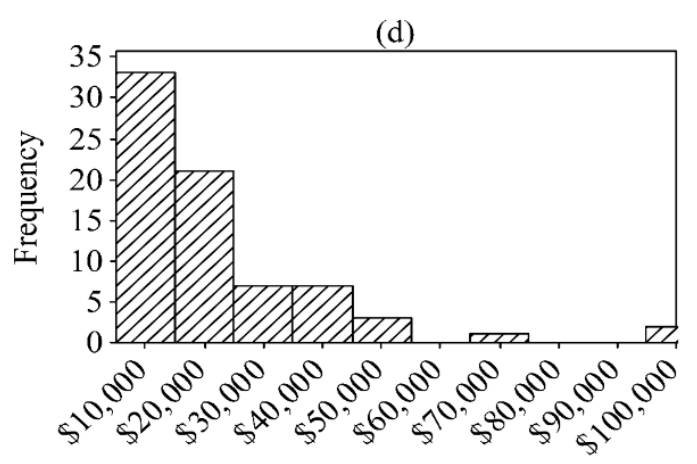

Total Repair Cost

Fig. 3. The right-skewed distribution of the repair cost that consumers spent over the last year (a). It ranges between $\$ 0$ and $\$ 1,000$ (b), or 1,000 and $\$ 10,000$ (c), or more than $\$ 10,000$ (d).

\subsubsection{Attitude toward Repair}

Consumers themselves may differ from each other in terms of attitude toward repair. A consumer may not like repairing products, while other may prefer to extend the products lifespan since s/he feels attached to them [42]. In this study, four qualitative factors have been considered to reflect consumers' attitude toward products repair including 1) desire to repair, 2) importance of repair cost to consumers, 3) importance of product repairability, and 4) the last product that they personally repaired.

First, they are asked about their willingness to repair the broken products even if there is no direct or convenient access to repair information at this moment. The related question is "How much more likely would you be to fix the item(s) you did not check if repair guides provider had a guide for it?" This factor is named desire to repair broken products. Also, the other two factors measure their concern about product repairability and repair cost at purchase decision time. These factors are named product repairability and repair cost importance. These factors are extracted from 'How important are product repairability and repair cost to your new purchase decisions?' questions.

It should be noted that we have separated 'the importance of repair cost to consumers' from the actual cost they have spent on repair (Section 3.2.3), since the former reveals the stated preference (attitude), while the latter shows their actual behavior and experience.

Finally, the 'last product that they personally have fixed' is the second factor under this category. Again, the respondents have selected the product from the available above mentioned options. We believe that the most recent repair experience might be more available in their mind when they make their future purchase decisions. The descriptive summary of all covariates is summarized in Table 3. The distribution of responses for the transformed questions can be easily followed. For example, 3615 respondents (43\% of total respondents) stated that the home appliances are easy to repair versus 
the rest of respondents who have opposite point of view.

\section{Regression Analysis}

In this section a predictive model has been developed to understand the impact of aforementioned predictive factors, representing consumers repair experience and attitude, on future purchase decision and recommendation. If it is found that there is a significant correlation between the two dependent variables, then a bivariate regression model can be used to estimate the probability that an observation with specific characteristics will come under one of the ordered categories [43]. In this paper, we utilize the bivariate ordered probit model. This model is very similar to the ordered logit model. The only difference is the distribution of the error terms. In ordered probit model, the error terms follow normal distribution, while they are logistically distributed in the ordered logit model [44]. Therefore, if $C L L_{i}$ and $P R L_{i}$ represent the first and second outcomes for consumer $i$, we have:

$$
\begin{aligned}
& C L L_{i}^{*}=\beta_{C L L}^{\prime} X_{i, C L L}+\varepsilon_{i, C L L}, \\
& C L L_{i}=j \text { if } \mu_{j-1}<C L L_{i}^{*}<\mu_{j}, j=0 \vee 1 \vee 2, \\
& P R L_{i}^{*}=\beta_{P R L}^{\prime} X_{i, P R L}+\varepsilon_{i, P R L}, \\
& P R L_{i}=j \text { if } \delta_{j-1}<P R L_{i}^{*}<\delta_{j}, j=0 \vee 1 \vee 2, \\
& \left(\begin{array}{l}
\varepsilon_{i, C L L} \\
\varepsilon_{i, P R L}
\end{array}\right) \sim N\left[\left(\begin{array}{l}
0 \\
0
\end{array}\right),\left(\begin{array}{ll}
1 & \rho \\
\rho & 1
\end{array}\right)\right] .
\end{aligned}
$$

In this model, $C L L_{i}{ }^{*}$ and $P R L_{i}{ }^{*}$ are the $i^{\text {th }}$ observed values for that latent variables measured in discrete form, $X_{i, C L L}$ and $X_{i, P R L}$ are the covariates values for observation $i$, and $\left\{\varepsilon_{C L L}, \varepsilon_{P R L}\right\}$ is the set of error terms normally distributed with mean zero and standard deviation one, and also strictly independent of covariates. Furthermore, $\left\{\beta_{C L L}, \beta_{P R L}\right.$, $\mu, \delta\}$ is the set of parameters that should be estimated, $\rho$ is the correlation coefficient between error terms, and $j$ is the integer ordered choice. Log-likelihood function uses the joint probability for $C L L_{i}=j$ and $P R L_{i}=k$ to estimate the parameters:

$$
\begin{aligned}
& \operatorname{Prob}\left(C L L_{i}=j, P R L_{i}=k \mid X_{i, C L L}, X_{i, P R L}\right) \\
& =\left[\begin{array}{c}
\Phi_{2}\left[\left(\mu_{j}-\beta_{C L L}^{\prime} X_{i, C L L}\right),\left(\delta_{k}-\beta_{P R L}^{\prime} X_{i, P R L}\right), \rho\right] \\
-\Phi_{2}\left[\left(\mu_{j-1}-\beta_{C L L}^{\prime} X_{i, C L L}\right),\left(\delta_{k}-\beta_{P R L}^{\prime} X_{i, P R L}\right), \rho\right]
\end{array}\right] \\
& -\left[\begin{array}{c}
\Phi_{2}\left[\left(\mu_{j}-\beta_{C L L}^{\prime} X_{i, C L L}\right),\left(\delta_{k-1}-\beta_{P R L}^{\prime} X_{i, P R L}\right), \rho\right] \\
-\Phi_{2}\left[\left(\mu_{j-1}-\beta_{C L L}^{\prime} X_{i, C L L}\right),\left(\delta_{k-1}-\beta_{P R L}^{\prime} X_{i, P R L}\right), \rho\right]
\end{array}\right],
\end{aligned}
$$

Where $\Phi_{2}$ (.) is the cumulative distribution function of the bivariate normal distribution. After estimation of parameters, a positive value means that the associated covariate will increase the probability of repurchases from the same brand or giving positive purchase recommendation to others. The negative value can be interpreted in an opposite way. To provide a better interpretation, the marginal effects are calculated as [45]:

$$
\begin{aligned}
& \frac{\partial \operatorname{Prob}(C L L=j)}{\partial X_{C L L}}= \\
& {\left[\Phi\left(\mu_{j-1}-\beta_{C L L} X_{C L L}\right)-\Phi\left(\mu_{j}-\beta_{C L L} X_{C L L}\right)\right] \beta_{C L L}} \\
& \frac{\partial \operatorname{Prob}(P R L=k)}{\partial X_{P R L}}= \\
& {\left[\Phi\left(\delta_{k-1}-\beta_{P R L} X_{P R L}\right)-\Phi\left(\delta_{k}-\beta_{P R L} \beta_{P R L}\right)\right] \beta_{P R L}}
\end{aligned}
$$

The marginal effect measures the positive or negative change in the probability of a particular output occurrence. For instance, if a marginal effect of $i^{\text {th }}$ level of factor $X$ is reported as $p$ for the $j^{\text {th }}$ output level of response factor $Y$, then we can say that it increases or decreases the probability of that level by $p$ based on its sign. It should be noted that the summation of all marginal effect values of a predictor factor for different levels of a response variable should be zero.

\section{Discussion of Results}

The bivariate ordered probit model is developed in SAS software (version 9.4; SAS Institute Inc.) In this dataset, the number of records that has missing data is unimportant to be worth consideration. Hence, to handle the missing data, a listwise deletion method is selected.

We have retained all variables that have significant impact on both outcomes at significance level of $5 \%$ in sequential analyses until finding the best model (Table 4) together with expected marginal effects (Table 5). The results show a significant 
correlation between consumer loyalty and recommendation levels $(\rho=0.294, p$-value $<0.0001)$.

First of all, if manufacturers make repair information easy to follow and share it with end users, it will be a strong incentive for consumers to repeat purchases from the same brand ( $p$-value< 0.0001 and $p$-value $=0.023$, respectively) and also recommend it to others ( $p$-value $=0.003$ and $p$ value<0.0001, respectively). However, repair manuals should not be designed in a way that leads the consumers to believe that the product is unreliable even if the product is completely repairable. Any product has a useful life time with a particular survivability function. In our dataset we face with failures that happened because of human errors (e.g. dropping the phone, water damage). Such failures are not usually covered by warranty services. In these cases, if a product is repairable, it will receive more consumer credit compared to usual failures and consumers value it more.

Consumers' decision process is not memoryless. The past events will influence consumers' future decisions either positively or negatively. Interestingly, consumers have a positive attitude toward repairing electronics. Among the dummy variables which represent 'the last product that consumer repair it personally', only 'electronics' indicator has significant impact on consumer loyalty $(p$-value $=0.002)$ and recommendation decision $(p$-value $=0.003)$. The possible reasons for this include: the large amount of repair information available for electronics on the web, the high penetration rate of electronics among consumers, and availability of electronics repair information. An untested assumption is the higher repairability of electronics compared to other products that should be examined. All these reasons should be proved by collecting more data. We expect to see negative impact of unsuccessful repair experiences and their associated reasons on both the repurchase and recommendation decisions. We find only two factors from the 'convenience of repair' category that have significant impact on a consumer's recommendation decision: expensive spare parts and complicated repair process.

However, it is not clear why expensive spare parts will increase the probability that consumers highly recommend the product to others, although it is not strongly significant $(p$-value $=0.035)$. The possible reasons could be due to the misleading question wording or the nature of data used which should be further analyzed in the next round of survey design and data collection. On the contrary, the complexity of repair decreases the chance of recommendation $(p$-value $=0.001)$.

Consumers' attitudes and the way they think about the product repairability are also important for product design. The results show that consumers are risk averse to buy less repairable products ( $p$ value $<0.0001$ for all corresponding level of repair desire) or recommend it ( $p$-value $<0.0001$ for all corresponding level of repair desire), even when they have relatively high desire to repair failed products. In addition, if repairability does not matter to a group of consumers, then they do not usually repeat purchases ( $p$-value $<0.0001$ for all corresponding level of repairability importance) or recommend it $(p$-value $<0.0001$ for all corresponding level of repairability importance) just based on repairability factor.

There is no evidence that the cost spent on repair over the last year has a significant impact on the first outcome $(p$-value $=0.615)$. On the other hand, the cost has a significant but not very strong impact on the second outcome ( $p$-value $=0.046)$. Though we expect to see stronger relationship between this predictor and the outcomes (i.e., a loyal consumer who highly recommend a repairable product to others would spend more on repair as well.), the sample data does not statistically support this hypothesis.

Finally, Table 5 shows the importance of factors based on the values of marginal effects. For instance, if a consumer does not care about the product repairability at all, this point decreases the probability of being a loyal consumer to a brand by 0.359. It is the highest value for changing the probability. On the other hand, every time that consumer uses the shared repair information, the probability of being loyal will increase by 0.009 . A similar interpretation can be done for the purchase recommendation. 
Table 3. The covariates descriptive summary

\begin{tabular}{|c|c|c|c|c|c|}
\hline Binary independent variables & No. $(0$ vs. 1$)$ & $\%(0$ vs. 1$)$ & $\begin{array}{l}\text { Total } \\
\text { No. }\end{array}$ & $\begin{array}{c}\text { P-value } \\
\text { (CLL) }\end{array}$ & $\begin{array}{c}\text { P-value } \\
(\text { PRL })\end{array}$ \\
\hline \multicolumn{6}{|l|}{ Repair information propagation } \\
\hline Usefulness of repair information ( 1 if the respondent selects yes, 0 otherwise) & $(749,7654)$ & $(89,91.1)$ & 8403 & $0.000^{*}$ & $0.000^{*}$ \\
\hline \multicolumn{6}{|l|}{ Convenience of repair } \\
\hline $\begin{array}{l}\text { Product repair convenience ( } 1 \text { if the electronic devices are easy to repair for respondent, } 0 \\
\text { otherwise) }\end{array}$ & $(1452,6951)$ & $(17.3,82.7)$ & 8403 & 0.534 & 0.609 \\
\hline $\begin{array}{l}\text { Product repair convenience ( } 1 \text { if the small home appliances are easy to repair for respondent, } 0 \\
\text { otherwise) }\end{array}$ & $(3627,4776)$ & $(43.2,56.8)$ & 8403 & 0.648 & 0.248 \\
\hline $\begin{array}{l}\text { Product repair convenience ( } 1 \text { if the large home appliances are easy to repair for respondent, } 0 \\
\text { otherwise) }\end{array}$ & $(4788,3615)$ & $(57,43)$ & 8403 & 0.965 & 0.638 \\
\hline Product repair convenience ( 1 if the vehicles are easy to repair for respondent, 0 otherwise) & $(3047,5356)$ & $(36.3,63.7)$ & 8403 & 0.893 & 0.962 \\
\hline Product repair convenience ( 1 if the clothing is easy to repair for respondent, 0 otherwise) & $(6306,2097)$ & $(75,25)$ & 8403 & 0.255 & 0.641 \\
\hline Product repair convenience ( 1 if the Furniture is easy to repair for respondent, 0 otherwise) & $(4488,3915)$ & $(53.4,46.6)$ & 8403 & 0.529 & 0.995 \\
\hline Unavailability of spare parts ( 1 if the respondent could not find the parts, 0 otherwise) & $(7010,1393)$ & $(83.4,16.6)$ & 8403 & 0.801 & 0.189 \\
\hline Expensive spare parts ( 1 if the parts were too expensive, 0 otherwise) & $(6984,1419)$ & $(83.1,16.9)$ & 8403 & 0.143 & $0.000^{*}$ \\
\hline $\begin{array}{l}\text { Unavailability of required tools ( } 1 \text { if the respondent could not find the required repair tool, } 0 \\
\text { otherwise) }\end{array}$ & $(7017,1386)$ & $(83.5,16.5)$ & 8403 & 0.821 & 0.208 \\
\hline Time-consuming repair ( 1 if repair was too time consuming, 0 otherwise) & $(7321,1082)$ & $(87.1,12.9)$ & 8403 & 0.163 & 0.863 \\
\hline Complexity of repair ( 1 if the respondent could not figure the repair out, 0 otherwise) & $(6177,2226)$ & $(73.5,26.5)$ & 8403 & 0.120 & $0.000^{*}$ \\
\hline $\begin{array}{l}\text { Unavailability of required manuals ( } 1 \text { if the respondent could not find the required repair } \\
\text { manual, } 0 \text { otherwise) }\end{array}$ & $(7351,1052)$ & $(87.5,12.5)$ & 8403 & $0.001^{*}$ & $0.004^{*}$ \\
\hline \multicolumn{6}{|l|}{ Attitude toward repair } \\
\hline $\begin{array}{l}\text { Desire to repair broken products without repair information ( } 1 \text { if extremely-low motivation, } 0 \\
\text { otherwise) }\end{array}$ & $(7996,340)$ & $(95.9,4.1)$ & 8336 & $0.000^{*}$ & $0.000^{*}$ \\
\hline Desire to repair broken products without repair information ( 1 if low motivation, 0 otherwise) & $(7721,615)$ & $(92.6,7.4)$ & 8336 & $0.000^{*}$ & $0.000^{*}$ \\
\hline $\begin{array}{l}\text { Desire to repair broken products without repair information ( } 1 \text { if moderate motivation, } 0 \\
\text { otherwise) }\end{array}$ & $(6169,2167)$ & $(74,26)$ & 8336 & $0.000^{*}$ & $0.000^{*}$ \\
\hline Desire to repair broken products without repair information ( 1 if high motivation, 0 otherwise) & $(5223,3113)$ & $(62.7,37.3)$ & 8336 & $0.001^{*}$ & $0.007^{*}$ \\
\hline $\begin{array}{l}\text { Desire to repair broken products without repair information ( } 1 \text { if extremely-high motivation, } 0 \\
\text { otherwise) }\end{array}$ & $(6235,2101)$ & $(74.8,25.2)$ & 8336 & $0.000^{*}$ & $0.000^{*}$ \\
\hline Importance of repair cost ( 1 if repair cost matters not at all to the respondent, 0 otherwise) & $(7941,462)$ & $(94.5,5.5)$ & 8403 & $0.000^{*}$ & $0.000^{*}$ \\
\hline Importance of repair cost ( 1 if repair cost matters somewhat to the respondent, 0 otherwise) & $(2941,5462)$ & $(35,65)$ & 8403 & $0.000^{*}$ & $0.000^{*}$ \\
\hline Importance of repair cost ( 1 if repair cost matters entirely to the respondent, 0 otherwise) & $(5924,2479)$ & $(70.5,29.5)$ & 8403 & $0.000^{*}$ & $0.000^{*}$ \\
\hline $\begin{array}{l}\text { Importance of product repairability ( } 1 \text { if product repairability matters not at all to the respondent, } \\
0 \text { otherwise) }\end{array}$ & $(8013,390)$ & $(95.4,4.6)$ & 8403 & $0.000^{*}$ & $0.000^{*}$ \\
\hline $\begin{array}{l}\text { Importance of product repairability ( } 1 \text { if product repairability matters somewhat to the } \\
\text { respondent, } 0 \text { otherwise) }\end{array}$ & $(3420,4916)$ & $(40.7,59.3)$ & 8403 & $0.000^{*}$ & $0.000^{*}$ \\
\hline $\begin{array}{l}\text { Importance of product repairability ( } 1 \text { if product repairability matters entirely to the respondent, } \\
0 \text { otherwise) }\end{array}$ & $(5361,3097)$ & $(63.8,36.2)$ & 8403 & $0.000^{*}$ & $0.000^{*}$ \\
\hline $\begin{array}{l}\text { last repaired product ( } 1 \text { if an electronic device was the last thing that respondent repaired it, } 0 \\
\text { otherwise) }\end{array}$ & $(1299,7095)$ & $(15.5,84.5)$ & 8394 & $0.000^{*}$ & $0.000^{*}$ \\
\hline $\begin{array}{l}\text { last repaired product ( } 1 \text { if a small home appliance was the last thing that respondent repaired it, } \\
0 \text { otherwise) }\end{array}$ & $(8128,266)$ & $(96.8,3.2)$ & 8394 & $0.021^{*}$ & $0.001^{*}$ \\
\hline $\begin{array}{l}\text { last repaired product ( } 1 \text { if a small home appliance was the last thing that respondent repaired it, } \\
0 \text { otherwise) }\end{array}$ & $(7957,437)$ & $(94.8,5.2)$ & 8394 & $0.000^{*}$ & $0.019^{*}$ \\
\hline last repaired product ( 1 if a vehicle was the last thing that respondent repaired it, 0 otherwise) & $(7991,403)$ & $(95.2,4.8)$ & 8394 & $0.014^{*}$ & 0.339 \\
\hline $\begin{array}{l}\text { last repaired product ( } 1 \text { if an item of clothing was the last thing that respondent repaired it, } 0 \\
\text { otherwise) }\end{array}$ & $(8321,73)$ & $(99.1,0.9)$ & 8394 & 0.542 & $0.012^{*}$ \\
\hline $\begin{array}{l}\text { last repaired product ( } 1 \text { if a piece of furniture was the last thing that respondent repaired it, } 0 \\
\text { otherwise) }\end{array}$ & $(8274,120)$ & $(98.6,1.4)$ & 8394 & $0.045^{*}$ & 0.054 \\
\hline
\end{tabular}
otherwise)

Continuous independent variables

Repair information propagation

Frequency of repair information usage

(The number of times that consumer have

used shared repair information)

Repair Cost

Cost spent on repair

**(Low, Medium, High)

CLL

\begin{tabular}{l|ll} 
Total No. & Mean & Std.
\end{tabular}

$(5.9,7.3,9.3)^{* *} \quad(11.9,24.4,31.3)$

$(11.9,24.4,31.3) \quad 0.002^{*}$

P-value
$0.002^{*}$

\begin{tabular}{l|l} 
& \\
& \\
& \\
& \\
& \\
\end{tabular}

Mean

$(4.6,7.4,11.6) \quad(10,26.7,33.6)$

$0.000^{*}$

7893

$(872,743,790)$

$(2750,2637,3059)$

0.615

$(591,769,856)$

(1166, 2835, 3363)

$0.046^{*}$ 
Table 4. Results of the bivariate ordered probit model: the list of factors influencing future purchase and recommendation decisions

\begin{tabular}{|c|c|c|c|c|c|c|}
\hline \multirow[b]{2}{*}{ Variables } & \multicolumn{3}{|c|}{$C L L$} & \multicolumn{3}{|c|}{$P R L$} \\
\hline & Coefficient & Std. Dev. & $P$-value & Coefficient & Std. Dev. & $P$-value \\
\hline Constant & 1.933 & 0.091 & $<0.0001$ & 1.644 & 0.088 & $<0.0001$ \\
\hline \multicolumn{7}{|l|}{ Repair information propagation } \\
\hline $\begin{array}{l}\text { Frequency of repair information usage (The number of times that } \\
\text { consumer have used shared repair information) }\end{array}$ & 0.002 & 0.001 & 0.023 & 0.006 & 0.001 & $<0.0001$ \\
\hline $\begin{array}{l}\text { Usefulness of repair information ( } 1 \text { if the respondent select yes, } 0 \\
\text { otherwise) }\end{array}$ & 0.256 & 0.065 & $<0.0001$ & 0.136 & 0.051 & 0.003 \\
\hline \multicolumn{7}{|l|}{ Convenience of repair } \\
\hline $\begin{array}{l}\text { Expensive spare parts ( } 1 \text { if the parts were too expensive, } 0 \\
\text { otherwise) }\end{array}$ & - & - & - & 0.01 & 0.047 & 0.035 \\
\hline $\begin{array}{l}\text { Complexity of repair ( } 1 \text { if the respondent could not figure the repair } \\
\text { out, } 0 \text { otherwise) }\end{array}$ & - & - & - & -0.154 & 0.04 & 0.001 \\
\hline \multicolumn{7}{|l|}{ Attitude toward repair } \\
\hline $\begin{array}{l}\text { Desire to repair broken products without repair information ( } 1 \text { if } \\
\text { extremely-low motivation, } 0 \text { otherwise) }\end{array}$ & -0.432 & 0.093 & $<0.0001$ & -0.447 & 0.091 & $<0.0001$ \\
\hline $\begin{array}{l}\text { Desire to repair broken products without repair information ( } 1 \text { if } \\
\text { low motivation, } 0 \text { otherwise) }\end{array}$ & -0.407 & 0.076 & $<0.0001$ & -0.428 & 0.075 & $<0.0001$ \\
\hline $\begin{array}{l}\text { Desire to repair broken products without repair information ( } 1 \text { if } \\
\text { moderate motivation, } 0 \text { otherwise) }\end{array}$ & -0.377 & 0.0518 & $<0.0001$ & -0.408 & 0.0502 & $<0.0001$ \\
\hline $\begin{array}{l}\text { Desire to repair broken products without repair information ( } 1 \text { if } \\
\text { high motivation, } 0 \text { otherwise) }\end{array}$ & -0.304 & 0.048 & $<0.0001$ & -0.241 & 0.046 & $<0.0001$ \\
\hline $\begin{array}{l}\text { Importance of product repairability ( } 1 \text { if product repairability } \\
\text { matters not at all to the respondent, } 0 \text { otherwise) }\end{array}$ & -0.961 & 0.09 & $<0.0001$ & -1.483 & 0.091 & $<0.0001$ \\
\hline $\begin{array}{l}\text { Importance of product repairability ( } 1 \text { if product repairability } \\
\text { matters somewhat to the respondent, } 0 \text { otherwise) }\end{array}$ & -0.48 & 0.04 & $<0.0001$ & -0.767 & 0.04 & $<0.0001$ \\
\hline $\begin{array}{l}\text { last repaired product ( } 1 \text { if an electronic device was the last thing } \\
\text { that respondent repaired it, } 0 \text { otherwise) }\end{array}$ & 0.16 & 0.051 & 0.002 & 0.152 & 0.05 & 0.003 \\
\hline$\mu$ & 1.818 & 0.036 & $<0.0001$ & 1.765 & 0.03 & $<0.0001$ \\
\hline$\rho$ & 0.294 & 0.02 & $<0.0001$ & & & \\
\hline $\mathrm{LL}(0)$ & -14620 & & & & & \\
\hline $\operatorname{LL}(\beta)$ & -7113 & & & & & \\
\hline
\end{tabular}

Table 5. Expected marginal effects

\begin{tabular}{|c|c|c|c|c|c|c|}
\hline \multirow[b]{2}{*}{ Variables } & \multicolumn{3}{|c|}{$C L L$} & \multicolumn{3}{|c|}{$P R L$} \\
\hline & Low & Medium & High & Low & Medium & High \\
\hline \multicolumn{7}{|l|}{ Repair information propagation } \\
\hline $\begin{array}{l}\text { Frequency of repair information usage indicator (The number of } \\
\text { times that consumer have used shared repair information) }\end{array}$ & -0.0002 & -0.0006 & 0.0009 & -0.001 & -0.0006 & 0.002 \\
\hline $\begin{array}{l}\text { Usefulness of repair information indicator ( } 1 \text { if the respondent } \\
\text { select yes, } 0 \text { otherwise) }\end{array}$ & -0.025 & -0.07 & 0.095 & -0.029 & -0.013 & 0.041 \\
\hline \multicolumn{7}{|l|}{ Convenience of repair } \\
\hline $\begin{array}{l}\text { Expensive spare parts ( } 1 \text { if the parts were too expensive, } 0 \\
\text { otherwise) }\end{array}$ & - & - & - & -0.021 & -0.009 & 0.03 \\
\hline $\begin{array}{l}\text { Complexity of repair ( } 1 \text { if the respondent could not figure the repair } \\
\text { out, } 0 \text { otherwise) }\end{array}$ & - & - & - & 0.033 & 0.014 & -0.047 \\
\hline \multicolumn{7}{|l|}{ Attitude toward repair } \\
\hline $\begin{array}{l}\text { Desire to repair broken products without repair information ( } 1 \text { if } \\
\text { extremely-low motivation, } 0 \text { otherwise) }\end{array}$ & 0.043 & 0.119 & -0.161 & 0.094 & 0.041 & -0.136 \\
\hline $\begin{array}{l}\text { Desire to repair broken products without repair information ( } 1 \text { if } \\
\text { low motivation, } 0 \text { otherwise) }\end{array}$ & 0.04 & 0.112 & -0.152 & 0.09 & 0.04 & -0.13 \\
\hline $\begin{array}{l}\text { Desire to repair broken products without repair information ( } 1 \text { if } \\
\text { moderate motivation, } 0 \text { otherwise) }\end{array}$ & 0.037 & 0.104 & -0.141 & 0.086 & 0.038 & -0.124 \\
\hline $\begin{array}{l}\text { Desire to repair broken products without repair information ( } 1 \text { if } \\
\text { high motivation, } 0 \text { otherwise) }\end{array}$ & 0.03 & 0.084 & -0.114 & 0.051 & 0.022 & -0.073 \\
\hline $\begin{array}{l}\text { Importance of product repairability ( } 1 \text { if product repairability } \\
\text { matters not at all to the respondent, } 0 \text { otherwise) }\end{array}$ & 0.095 & 0.264 & -0.359 & 0.313 & 0.137 & -0.45 \\
\hline $\begin{array}{l}\text { Importance of product repairability ( } 1 \text { if product repairability } \\
\text { matters somewhat to the respondent, } 0 \text { otherwise) }\end{array}$ & 0.047 & 0.132 & -0.179 & 0.162 & 0.07 & -0.233 \\
\hline $\begin{array}{l}\text { last repaired product ( } 1 \text { if an electronic device was the last thing } \\
\text { that respondent repaired it, } 0 \text { otherwise) }\end{array}$ & -0.016 & -0.044 & 0.06 & -0.032 & -0.014 & 0.046 \\
\hline
\end{tabular}


The results could be critiqued as not being generalizable since a specific group of respondents is selected. iFixit.com has over a million members. $45 \%$ of them are from U.S. and the rest of users are around the world. In [17], Scott and Weaver compared iFixit users with regular users. They showed the robustness of their findings for different levels of propensity for repair across two samples of iFixit and MTurk users. The results of their research illustrated that the two groups have similar attitude towards repair somehow. However, they planned to redesign the survey and data collection method to have more diversity among the respondents.

\section{Concluding Remarks}

In this study, an industry dataset has been analyzed to extract consumers' actual point of views toward product repairability, and the factors that make it difficult for consumers to fix their products themselves under the main categories of product, economic, and consumer-related factors. The final objective was to test whether and how product repairability will influence consumers' future purchase choices and brand recommendations to family and friends. A bivariate ordered probit model has been employed to connect the consumers' attitude toward repurchasing repairable products and also their recommendation decisions with their prior repair experiences. The consumers' attitude toward product repair and prior repair experiences has been derived using four different categories of factors including accessibility and usefulness of repair information, convenience of repair, the cost spent on repair, and the consumers' attitude to product repairability. A relatively good prediction model has been found for future purchase decisions and recommendations based on predictor factors. We find that sharing repair manuals, usefulness of repair information, repair capability of consumers (clear about repair process), higher desirability to repair a product, and finally consideration of reparability and repair cost at purchase time will have a positive impact on future repurchase and purchase recommendation of a repairable product. On the other hand, the impact of other factors such as the cost spent on repair is not found significant. The result of this survey will help designers identify the revisions needed in the product design as well as manufacturers repair strategies.

A limitation of the current study is the lack of diversity in the group of respondents. All respondents are aware of repair guides and providers and have experienced repair activities individually. Also, they show an interest in repairable product while the level of interest would vary. In addition, the sociodemographic characteristics, e.g. age and education, of respondents may have an effect on the consumer decision-making. Therefore, the future surveys should include different groups of consumers with various demographic information. Another limitation is the survey design. A few questions were somehow ambiguous to respondents. As a consequence, we had to delete the inaccurate responses that resulted in more missing data.

In addition, there is a trade-off between the cost of designing repairable products, product price and marketability, which can be analyzed in an integrated optimization model. Moreover, as a reasonable assumption, repairable and durable products will be used longer. Therefore, it is worthwhile to investigate the waste generation stream based on product durability. Repairability quantification is another topic that should be covered as part of future studies.

It is important to know what degree of repairability will encourage consumers to resume product usage and when consumers will be convinced enough to recommend a product to others. As we discussed earlier, unlike reliability, consumers may not primarily looking for a repairable product. Then, how manufacturers should make a trade-off between product's design cost and repairability at the early phase of product design is another research question. Improving the mentioned design for ease-of-repair features poses cost and technical challenges at the same time and, consequently, results in increase of prime cost of a product. The design problem can be modeled as an optimization problem to determine the optimal level of decision variables. It would be also useful, as a future study, to quantify the rebound effects of increasing repairability in order to select the sufficient level 
that minimizes the rebound effects besides achieving the economic objective.

\section{Acknowledgements}

This material is based upon work supported by the National Science Foundation - USA under grant \# CMMI-1435908. Any opinions, findings, and conclusions or recommendations expressed in this material are those of the authors and do not necessarily reflect the views of the National Science Foundation.

\section{References}

[1] S. Umair, A. Björklund, and E. E. Petersen, "Social impact assessment of informal recycling of electronic ICT waste in Pakistan using UNEP SETAC guidelines," Resour. Conserv. Recycl., vol. 95, pp. 4657, 2015.

[2] S. Lebel, "Fast machines, slow violence: ICTs, planned obsolescence, and e-waste," Globalizations, no. ahead-of-print, pp. 110, 2015.

[3] A. M. King, S. C. Burgess, W. Ijomah, and C. A. McMahon, "Reducing waste: repair, recondition, remanufacture or recycle?," Sustain. Dev., vol. 14, no. 4, pp. 257-267, Oct. 2006.

[4] N. van Nes and J. Cramer, "Influencing product lifetime through product design," Bus. Strateg. Environ., vol. 14, no. 5, pp. 286-299, Sep. 2005.

[5] E. Cohen-Rosenthal, "Making sense out of industrial ecology: a framework for analysis and action," J. Clean. Prod., vol. 12, no. 8, pp. 1111-1123, 2004.

[6] M. T. Adjei, S. M. Noble, and C. H. Noble, "The influence of $\mathrm{C} 2 \mathrm{C}$ communications in online brand communities on customer purchase behavior," J. Acad. Mark. Sci., vol. 38, no. 5, pp. 634-653, 2010.

[7] C.-H. Park and Y.-G. Kim, "Identifying key factors affecting consumer purchase behavior in an online shopping context," Int. J. Retail Distrib. Manag., vol. 31, no. 1, pp. 16-29, 2003.

[8] M. E. H. Creusen and J. P. L. Schoormans, "The different roles of product appearance in consumer choice*," J. Prod. Innov. Manag., vol. 22, no. 1, pp. 63-81, 2005.
[9] R. Teratanavat and N. H. Hooker, "Consumer valuations and preference heterogeneity for a novel functional food," J. Food Sci., vol. 71, no. 7, pp. S533-S541, 2006.

[10] D. J. Flint, C. P. Blocker, and P. J. Boutin, "Customer value anticipation, customer satisfaction and loyalty: An empirical examination," Ind. Mark. Manag., vol. 40, no. 2, pp. 219-230, 2011.

[11] P. Nieuwenhuis, "From banger to classic a model for sustainable car consumption?," Int. J. Consum. Stud., vol. 32, no. 6, pp. 648-655, Nov. 2008.

[12] T. H. Baek, J. Kim, and J. H. Yu, "The differential roles of brand credibility and brand prestige in consumer brand choice," Psychol. Mark., vol. 27, no. 7, pp. 662-678, Jul. 2010.

[13] W. Verbeke, J. Scholderer, and L. Lähteenmäki, "Consumer appeal of nutrition and health claims in three existing product concepts," Appetite, vol. 52, no. 3, pp. 684-692, Jun. 2009.

[14] J. Yang, W. Kim, N. Amblee, and J. Jeong, "The heterogeneous effect of WOM on product sales: why the effect of WOM valence is mixed?," Eur. J. Mark., vol. 46, no. 11/12, pp. 1523-1538, 2012.

[15] C. Fotopoulos and A. Krystallis, "Quality labels as a marketing advantage: The case of the 'PDO Zagora' apples in the Greek market," Eur. J. Mark., vol. 37, no. 10, pp. 1350-1374, 2003.

[16] J. A. Spack, V. E. Board, L. M. Crighton, P. M. Kostka, and J. D. Ivory, 'It's easy being green: The effects of argument and imagery on consumer responses to green product packaging," Environ. Commun. A J. Nat. Cult., vol. 6, no. 4, pp. 441-458, 2012.

[17] K. A. Scott and S. T. Weaver, "To Repair or Not to Repair: What is the Motivation?," J. Res. Consum., no. 26, p. 1, 2014.

[18] T. Cooper, "Slower consumption," J. Ind. Ecol., vol. 9, no. 1-2, pp. 51-68, 2005.

[19] E. M. Okada, "Trade- ins, mental accounting, and product replacement decisions," J. Consum. Res., vol. 27, no. 4, pp. 433-446, 2001. 
[20] J. Guiltinan, "Creative destruction and destructive creations: environmental ethics and planned obsolescence," J. Bus. Ethics, vol. 89, no. 1, pp. 19-28, 2009.

[21] T. Page, "Product attachment and replacement: implications for sustainable design," Int. J. Sustain. Des., vol. 2, no. 3, pp. 265-282, 2014.

[22] B. L. Bayus, "The consumer durable replacement buyer," J. Mark., pp. 42-51, 1991.

[23] K. L. Haws, R. W. Naylor, R. A. Coulter, and W. O. Bearden, "Keeping it all without being buried alive: Understanding product retention tendency," J. Consum. Psychol., vol. 22, no. 2, pp. 224-236, Apr. 2012.

[24] T. C. Boyd and D. M. McCCNOCHA, "Consumer household materials and logistics management: inventory ownership cycle," J. Consum. Aff., vol. 30, no. 1, p. 218, 1996.

[25] J. McCollough, "Consumer discount rates and the decision to repair or replace a durable product: a sustainable consumption issue," J. Econ. Issues, vol. 44, no. 1, pp. 183-204, 2010.

[26] S. Hills and D. Worthing, "Private home, public cultural asset: the maintenance behaviour of listed building owneroccupiers," J. Hous. Built Environ., vol. 21, no. 2, pp. 203-213, 2006.

[27] Longer Lasting Products: Alternatives To The Throwaway Society. Gower Publishing, Ltd., 2012.

[28] T. Cooper, "Inadequate Life?Evidence of Consumer Attitudes to Product Obsolescence," J. Consum. Policy, vol. 27, no. 4, pp. 421-449, Dec. 2004.

[29] C. Bakker, F. Wang, J. Huisman, and M. den Hollander, "Products that go round: exploring product life extension through design," J. Clean. Prod., vol. 69, pp. 10-16, 2014.

[30] T. Cooper, "Slower Consumption Reflections on Product Life Spans and the 'Throwaway Society," J. Ind. Ecol., vol. 9, no. 1-2, pp. 51-67, Feb. 2008.

[31] W. L. Chang, "Optimal single-replacement for repairable products with different failure rate under a finite planning horizon," Int. J.
Syst. Sci., vol. 46, no. 6, pp. 1003-1009, Jun. 2013.

[32] J. D. Cripps and R. J. Meyer, "Heuristics and Biases in Timing the Replacement of Durable Products," J. Consum. Res., vol. 21, no. 2, pp. 304-18, 1994.

[33] J. Scelfo, "Appliance Anxiety: Replace It or Fix It?," The New York Times, 27-May2009.

[34] E. M. Okada, "Trade- ins, Mental Accounting, and Product Replacement Decisions," J. Consum. Res., vol. 27, no. 4, pp. 433-446, Mar. 2001.

[35] L. A. Frye-Levine, "Sustainability Through Design Science: Re-Imagining Option Spaces Beyond Eco-Efficiency," Sustain. Dev., vol. 20, no. 3, pp. 166-179, May 2012.

[36] F. H. Buttel, "The Treadmill of Production An Appreciation, Assessment, and Agenda for Research," Organ. Environ., vol. 17, no. 3, pp. 323-336, 2004.

[37] L. A. Frye- Levine, "Sustainability Through Design Science: Re- Imagining Option Spaces Beyond Eco- Efficiency," Sustain. Dev., vol. 20, no. 3, pp. 166-179, 2012.

[38] J. M. Polimeni and R. I. Polimeni, “Jevons' Paradox and the myth of technological liberation," Ecol. Complex., vol. 3, no. 4, pp. 344-353, Dec. 2006.

[39] B. Alcott, "Jevons' paradox," Ecol. Econ., vol. 54, no. 1, pp. 9-21, 2005.

[40] F. Figge, W. Young, and R. Barkemeyer, "Sufficiency or efficiency to achieve lower resource consumption and emissions? The role of the rebound effect," J. Clean. Prod., vol. 69, pp. 216-224, Apr. 2014.

[41] N. Gregson, A. Metcalfe, and L. Crewe, "Practices of Object Maintenance and Repair How consumers attend to consumer objects within the home," J. Consum. Cult., vol. 9, no. 2, pp. 248-272, 2009.

[42] R. Mugge, J. P. L. Schoormans, and H. N. J. Schifferstein, "Design strategies to postpone consumers' product replacement: The value of a strong person-product relationship," Des. J., vol. 8, no. 2, pp. 3848, 2005. 
[43] W. H. Greene and D. A. Hensher, Modeling ordered choices: a primer. Cambridge University Press, 2010.

[44] V. K. Borooah, Logit and probit: Ordered and multinomial models, no. 138. Sage, 2002.
[45] B. J. Russo, P. T. Savolainen, W. H Schneider IV, and P. C. Anastasopoulos, "Comparison of factors affecting injury severity in angle collisions by fault status using a random parameters bivariate ordered probit model," Anal. Methods Accid. Res., vol. 2, no. 0, pp. 21-29, Apr. 2014. 